\title{
INTEGRAÇÃO DOCENTE-ASSISTENCIAL SOB A ÓTICA DOS PROFISSIONAIS DE SAÚDE
}

\author{
Joselany Áfio Caetano¹, Rita de Cássia Moura Diniz², Enedina Soares ${ }^{3}$
}

\begin{abstract}
RESUMO: Objetivou-se neste estudo investigar a integração docente-assistencial, sob a visão dos profissionais de saúde, nas instituições de saúde onde são desenvolvidos estágios curriculares dos cursos de graduação da área da saúde de uma universidade particular, no município de Fortaleza-CE. Foram entrevistados 20 profissionais de saúde. Das entrevistas emergiram quatro categorias de análise temática: integração docente-assistencial; contribuição do profissional de saúde no processo ensino-aprendizagem dos alunos; atividades desenvolvidas pelos docentes dentro da instituição e estratégias para fortalecer a parceria com o serviço. Os resultados denotam ser a relação dos profissionais de saúde com os docentes bastante positiva e suas contribuições estão relacionadas com a disposição em favorecer o campo de prática docente/discente. Como a integração docente assistencial envolve questões estruturais e conjunturais muito mais complexas, são necessários momentos de reflexão sobre como articular esses dois contextos aparentemente desconectados - universidade e serviços.
\end{abstract}

PALAVRAS-CHAVE: Serviço de integração docente-assistencial; Educação superior; Serviços de saúde para estudantes.

\section{TEACHING-CARE INTEGRATION FROM THE HEALTH PROFESSIONALS PERSPECTIVE}

\begin{abstract}
This descriptive study with a qualitative approach aimed to examine the integration between teaching and care from the perspective of health professionals, at teaching health institutions where undergraduate health courses from a private university hold their traineeships, located in Fortaleza-CE, Brazil. Twenty health professionals were interviewed. Four thematic analysis categories emerged from the participants' statements: teaching-care integration; health professionals' contribution in the students' teaching-learning process; activities developed by faculty members within the institution and strategies for strengthening partnerships with the care service. According to the results, the health professionals' relation with the faculty members is quite positive and their contributions are related to the willingness to favor the teacher/student practice area. As the teaching-care integration involves much more complex structural and conjuncture issues, moments of reflection are needed about how to articulate these apparently disconnected contexts - university and services.
\end{abstract}

KEYWORDS: Teaching-care integration services; Education, higher; Student health services.

\section{INTEGRACIÓN DOCENTE-ASISTENCIAL BAJO LA ÓPTICA DE LOS PROFESIONALES DE SALUD}

RESUMEN: Se objetivó en este estudio investigar la integración docente-asistencial, bajo la visión de los profesionales de salud, en las instituciones de salud donde son desarrolladas pasantías curriculares de los cursos de graduación del área de la salud de una universidad particular, en Fortaleza-CE, Brasil. Fueron entrevistados 20 profesionales de salud. De las entrevistas emergieron cuatro categorías de análisis temático: integración descriptiva docente-asistencial; contribución del profesional de salud en el proceso enseñanza-aprendizaje de los alumnos; actividades desarrolladas por los docentes dentro de la institución y estrategias para fortalecer la colaboración con el servicio. Los resultados denotan ser la relación de los profesionales de salud con los docentes es bastante positiva y sus contribuciones están relacionadas con la disposición en favorecer el campo de práctica docente/discente. Como la integración docente-asistencial envuelve cuestiones estructurales y coyunturales mucho más complexas, son necesarios momentos de reflexión sobre cómo articular esos dos contextos aparentemente desconectados - universidad y servicios.

PALABRAS CLAVE: Servicios de integración docente-asistencial; Educación superior; Servicios de salud para estudiantes.

\footnotetext{
${ }^{1}$ Enfermeira. Doutora em Enfermagem. Professor Adjunto da Universidade Federal do Ceará-UFCE.

${ }^{2}$ Professor Adjunto da UFCE. Doutoranda do Programa de Pós-Graduação em Educação Brasileira da UFC.

${ }^{3}$ Livre Docente. Professor Permanente do Curso de Pós-Graduação da Universidade Federal do Estado do Rio de Janeiro-UNIRIO.
}

Autor correspondente:

Joselany Afio Caetano

Universidade Federal do Ceará

Rua Aécio Cabral, 300 - 60135-480 - Fortaleza-CE, Brasil

Recebido: 14/03/09

E-mail: joselany@ufc.br

Aprovado: 08/09/09

Cogitare Enferm 2009 Out/Dez; 14(4):638-44 


\section{INTRODUÇÃO}

A integração docente-assistencial-IDA tem sido objeto de preocupação das Universidades há longa data, exigindo dos seus participantes esforços tanto dos docentes como dos profissionais de saúde que atuam na assistência com vistas a atingir os moldes desejáveis de aplicação. No Brasil, a partir da reforma universitária de 1968, quando a IDA foi considerada elemento importante para a qualificação profissional a ser formada e, também, para a melhoria da qualidade da assistência a ser prestada $^{(1)}$, intensificaram-se os estudos acerca da mencionada integração.

Para iniciarmos esta discussão, cabe uma diferenciação conceitual entre integração ensinoserviço e integração docente-assistencial. Nosso interesse pela integração docente-assistencial é mais didático-pedagógica, já que a integração ensino-serviço é mais estrutural, mais institucional ${ }^{(2)}$.

O programa de Integração DocenteAssistencial, um dos recursos utilizados pelo governo federal para aproximar o ensino e os serviços, tem sido apresentado como uma proposta de planejamento de saúde e educação para ajustar necessidades sociais e tecnológicas e é definido como:

a união de esforços em um processo crescente de articulação entre instituição de educação e de serviços de saúde, adequados às necessidades reais da população, à produção de conhecimentos e à formação de recursos humanos necessários em um determinado contexto da prática de serviços de saúde e de ensino ${ }^{(3: 52)}$.

Portanto, segundo esse conceito, o programa faz parte de um processo que requer participação da sociedade. Desse modo, através da realidade concreta, devem ser desenvolvidos os conteúdos acadêmicos e dos serviços, em atendimento às necessidades da população, implicando a redefinição do sistema formador e do prestador de serviços com uma postura crítica sobre a realidade ${ }^{(4)}$.

Entretanto, as políticas e estruturas dos serviços de saúde e de ensino dificultam ou até mesmo impossibilitam a implementação da IDA. Entre as principais dificuldades constam: a polarização dos envolvidos em grupos docentes e assistenciais, a filosofia e objetivos de trabalho divergentes entre as instituições envolvidas e a rigidez na definição nos papéis dos docentes e assistenciais ${ }^{(4)}$. Diante destas dificuldades os docentes se distanciam das situações práticas do cotidiano e passam a intensificar a teoria em detrimento das ações da pratica assistencial. Em contrapartida, os profissionais da assistência se envolvem de forma tão profunda com as atividades rotineiras do cotidiano de trabalho que deixam de lado a educação continuada e, pouco a pouco, se desatualizam ${ }^{(5)}$.

Por isso, conforme entendemos, a IDA é um meio para superar a dicotomia entre a teoria e a prática e, consequentemente, os alunos terão mais oportunidades para aplicar a teoria estudada nos campos de prática. A IDA também propicia melhor articulação entre os profissionais da assistência e os docentes ao ensejar reflexões sobre a qualidade da assistência prestada aos clientes. Assim, este estudo tem como objetivo investigar a integração docenteassistencial sob a visão dos profissionais de saúde das instituições onde são exercidas práticas assistenciais de saúde de uma universidade particular.

Integrar o ensino e a assistência implica uma atitude a ser construída no âmbito acadêmico e também profissional. Daí a importância de entendermos a visão dos profissionais de saúde sobre a temática, porquanto as discussões se transversalizam na busca de uma formação articulada, pressupondo relações profissionais engendradas por atitudes interdisciplinares e democráticas

\section{METODOLOGIA}

Trata-se de um estudo descritivo, com abordagem qualitativa, realizado em 13 instituições de saúde onde são desenvolvidos estágios dos cursos de graduação da área de saúde de uma universidade privada, do município de Fortaleza-CE, dos quais foram selecionados cinco cursos: enfermagem, terapia ocupacional, fisioterapia, odontologia e educação física. Atualmente existem 77 campos de prática. As práticas do curso de enfermagem acontecem em 23 locais; as de terapia ocupacional, em 22; as de fisioterapia, em 21; as de fonoaudiologia, em 15; as de odontologia, em 11 e as de educação física, em 8 . Vale ressaltar que em um campo de prática pode haver mais de um curso atuando.

A amostra foi aleatória e consta de 20 profissionais de saúde em atuação nas unidades onde existem campos de prática dos cursos de graduação na área da saúde, que estão em contato com os alunos na prática e que aceitaram participar do estudo.

Adotamos como critério de inclusão no estudo os profissionais de nível superior que estivessem em plena atividade no setor selecionado e na ocasião da visita à instituição aceitaram em participar da entrevista.

Para a produção de dados utilizamos um roteiro 
de entrevista semiestruturado, contendo dados de identificação e cinco questões subjetivas acerca da IDA. A coleta de dados foi realizada no período de fevereiro a maio de 2007, após contato dos autores deste estudo com cada participante, recebido o aceite em participar da pesquisa e assinatura do Termo de Consentimento Livre e Esclarecido. Como exigido, foram atendidas as determinações da Resolução 196/96 ${ }^{(6)}$ do Ministério da Saúde acerca de pesquisa com seres humanos. As entrevistas foram realizadas em local previamente selecionado e em horário anteriormente combinado. Os participantes foram identificados de acordo com sua categoria profissional, seguida de um número em arábico (enfermeiro-1, 2,...); (educador físico-1, 2...); (fisioterapeuta-1, 2...); (terapeuta ocupacional-1, 2,...); (odontólogo-1, 2...); (fonoaudiólogo-1, 2...).

Após a coleta, os dados foram organizados em consonância com as etapas propostas por Bardinn ${ }^{(7)}$, através do método de Análise de Conteúdo: a préanálise, a exploração do material e o tratamento dos resultados, a inferência e a interpretação, e expostos em categorias de análise. Para apresentação dos dados e análise, foram utilizados recortes de relatos dos profissionais de saúde.

\section{RESULTADOS}

Das questões respondidas emergiram quatro categorias de análise: integração docente-assistencial; contribuição do profissional de saúde no processo ensino-aprendizagem; atividades desenvolvidas pelos docentes dentro da instituição e estratégias para fortalecer a parceria com o serviço.

Todos os partícipes pesquisados foram unânimes em acreditar na integração docente-assistencial. Porém, um ponto importante a considerar é o conceito de integração deles, pois, como afirmam em seus depoimentos, acreditam numa integração quando existe boa relação com o docente ou quando os discentes realizam suas atividades nas unidades onde desenvolvem o estágio, independentemente da parceria com o docente.

\section{Integração docente-assistencial}

A relação dos profissionais de saúde com os docentes é apontada pelos participantes como bastante positiva, embasada em um vínculo de respeito e amizade, fator este favorável à integração do docente no serviço. A universidade em discussão prioriza nas suas contratações docentes com experiência prática.
Portanto, não contempla somente suas competências como docente, mas também a assistencial, inclusive muitos deles desempenham sua prática nas instituições onde mantêm vínculo empregatício. Dessa forma, mantêm bons relacionamentos com os profissionais da instituição:

Porque os profissionais desta instituição estão sempre à disposição dos alunos e seus professores como também há uma boa relação entre os profissionais (fisioterapeuta-3).

Respeito às normas, atenção e educação com funcionários e pacientes buscando uma integração geral (fisioterapeuta-2).

A docente sendo funcionária também do hospital possui envolvimento e abertura com as chefias para desenvolver o trabalho com os alunos (enfermeira-7).

Ao discorrer sobre IDA, os alunos apontam os seguintes termos: disposição, relação, respeito e envolvimento. Falam de IDA como uma relação harmônica, com destaque também na participação do aluno.

Nos serviços de saúde, as atividades de ensino se colocam num nível de complementação, de troca, e devem também contribuir para solucionar os problemas apresentados pela realidade. Parte-se do princípio segundo o qual o aluno não deve apenas servir de mão-de-obra complementar para o serviço, mas ser capaz de refletir a sua formação profissional à luz do sistema de saúde. Porém os profissionais de saúde precisam compreender o verdadeiro papel do alunado na instituição, pois, fica claro nas suas falas que a integração acontece quando tanto o docente como os alunos participam das tarefas diárias do serviço.

Na continuidade do atendimento da nossa clientela e estando disponíveis para nos ajudar, com as oficinas e palestras [...] (enfermeira-1).

$O$ docente e os alunos procuram estar sempre a par das rotinas e participam das atividades da unidade [...]. A parceria se mostra muito satisfatória, pois a participação nas atividades é muito grande [...] (enfermeira-6).

\section{[...] troca de experiências, disponibilidade de}


cooperação nos procedimentos e realização da sistematização da assistência de enfermagem [...]; seguem as normas e rotinas do hospital dando maior contribuição, executando maior número de tarefas (enfermeira-7).

Há uma integração com a rotina de atendimento diário, bem como dos protocolos e das sugestões no tratamento (fisioterapeuta-1).

Tais depoimentos revelam as atividades desempenhadas pelos alunos durante o estágio, como acompanhamento de pacientes, realização de oficinas e palestras, sistematização da assistência de enfermagem e execução de procedimentos. Há um destaque no aprender a fazer. Isto implica executar adequadamente procedimentos e técnicas, com vistas a reproduzir com exatidão o conteúdo teórico.

Como afirma a literatura, a repetição das atividades garantirá a retenção do conteúdo ensinado, e é indispensável para capacitar o aluno a responder a situações novas segundo um padrão estabelecido em situações anteriores $^{(8)}$. A ênfase em seguir rotina, normas, protocolos da unidade é evidente nos depoimentos. O que não deveria acontecer, pois o aprender a fazer não pode continuar a ter um significado restrito a preparar alguém para realizar procedimentos técnicos, mas, antes, deverá encerrar a dimensão cognitiva, a reflexão, o questionamento, mesmo sobre tarefas puramente materiais ${ }^{(9)}$.

A prática profissional envolve uma série de ações, as quais evidenciam um saber que se dá no fazer. Por isso, nesse caso, parece certo dizer que o conhecimento está na ação do profissional. Este conhecimento prático é adquirido por meio de determinada atividade e, a partir da experiência adquirida, as pessoas passam a dar respostas imediatas aos problemas enquadrados dentro da estrutura de outros problemas já resolvidos. Quando o profissional desenvolve suas ações, ele não se limita à deliberação de meios e, sim, passa a definir meio e fins de forma interativa. Neste momento, o profissional não separa o pensar do fazer ao elaborar uma decisão a ser mais tarde convertida em ação. Portanto, é essencial introduzir o aluno nos problemas que o desafiarão, levando-o a buscar formas de solucioná-los ${ }^{(10)}$. Isto está constatado nas falas a seguir:

Há uma troca de experiências que são fundamentais para o processo de aprendizagem dos alunos do curso de enfermagem $e$ o atendimento qualitativo do público alvo da instituição (enfermeira-1).

Os alunos praticam o que é ensinado nas aulas teóricas (tanto a parte manual como a parte dos aparelhos) (fisioterapeuta-1).

Por meio de atividades integradas com os demais profissionais da instituição, promovendo dinâmicas de grupo, palestras e festas em datas comemorativas, junto com a assistente social há integração, mas poderia haver mais se tivéssemos oportunidade de discussão de casos (terapeuta ocupacional-1).

É fundamental entender a importância de um currículo como práxis, ou seja, um currículo construído mediante uma interação entre refletir e atuar, dentro de um processo circular de planejamento-açãoavaliação; que se realiza num mundo real, em condições concretas; num mundo de interações; o currículo não deve existir exclusivamente para a aprendizagem, deve constituir-se em ato social, a práxis é construída no natural, pois, via situações de ensino-aprendizagem proporcionadas pelos currículos, os estudantes tornam-se ativos e partícipes da elaboração de seu próprio saber ${ }^{(11)}$.

Esse processo de mudança de concepção, lento por sua própria complexidade, requer necessariamente agregar docentes e profissionais, possibilitando-lhes experimentarem, refletirem e incorporarem novos conceitos, provocando mudanças de fato. É importante lembrar que a IDA acontece exatamente nos campos de estágio. No entanto, neste modelo, a integração não é sistemática, pois o contato dos docentes com o hospital ocorre apenas nos períodos de estágio dos alunos. Isto desvela uma descaracterização da IDA. Portanto, é preciso repensar a prática numa proposta de criar outros possíveis caminhos para consolidação da IDA, que sejam úteis para os pacientes, alunos, profissionais da assistência e docentes.

\section{Contribuição do profissional de saúde no processo ensino-aprendizagem}

Nas falas dos profissionais de saúde, conforme percebemos, sua contribuição está relacionada com sua disposição em ajudar quando solicitado ou em favorecer o campo de prática para professor-aluno por meio de 
seleção de pacientes com casos clínicos especiais, não execução de procedimentos técnicos, cedendo lugar para o aluno e também para a troca de experiência.

Dentro da proposta da IDA, os profissionais de saúde devem ser facilitadores. Isto é, aquela pessoa que facilita, torna mais fácil ou menos difícil algo que alguém tenha de realizar. Este facilitador seria uma pessoa com um significado extremamente representativa no processo ensino-aprendizagem para quem o reconhece como tal (aluno), porque o vê com conhecimento e boa comunicação ${ }^{(12)}$. É neste contexto que os partícipes deste estudo entendem:

[...] com questionamentos científicos, exemplos de profissionalismo ético e incentivar sempre o processo de aprendizagem (fisioterapeuta-1).

Procuro atender às solicitações sempre que são feitas [...]. Fazendo como já faço, orientando sobre as rotinas e todas as dúvidas que o aluno apresenta (enfermeira-5).

Buscar direcionar os casos mais interessantes para os alunos, sendo uma co-supervisora junto ao professor [...]. Levando-os a conhecer o local de trabalho, bem como a área de atuação na comunidade e mostrando a realidade local (odontólogo-1).

Através de orientações, recebendo bem os alunos e professores e estando à disposição para o esclarecimento de dúvidas [...]. Dando abertura para o docente e alunos realizarem um bom estágio (enfermeira-7).

Ser facilitador não é somente dar oportunidade para o aluno executar sua prática, esclarecer dúvidas, orientar sobre as rotinas e normas da instituição, direcionar os casos interessantes para discussão, conforme vimos nos relatos anteriores. É, sobretudo, promover situações estimuladoras; dar suporte humano; manter monitoramento da aprendizagem do aluno; facilitar e/ou encaminhar questões administrativas; manter a co-responsabilidade do aluno na avaliação ${ }^{(13)}$. Então, como podemos entender pelo relato dos profissionais de saúde, há dificuldades para IDA, e um dos pontos levantados é: para exercer a função de facilitador exige-se tempo, aspecto de certa forma dificultado pela falta de disponibilidade de tempo dos profissionais de saúde.

Como evidenciamos nos indicativos da IDA, uma das dificuldades de implantação é a sobrecarga de trabalho tanto do docente quanto do profissional da assistência. No caso dos profissionais de saúde há inúmeras tarefas a serem cumpridas no cotidiano de trabalho ${ }^{(14-15)}$. Às vezes temos a participação dos profissionais nos estágios supervisionados. Conforme exigido pelas diretrizes curriculares dos cursos de graduação da saúde em hospitais gerais e especializados, ambulatórios, rede básica de serviços de saúde e comunidades nos dois últimos semestres do curso, é assegurada efetiva participação dos profissionais de serviço onde acontece o referido estágio.

\section{Atividades desenvolvidas pelos docentes dentro da instituição}

Entre as ações desenvolvidas pelos docentes incluem-se prestar assistência, distribuir tarefas, supervisionar a prática e acompanhar os alunos. Portanto, são entendidas como as atividades que os docentes desempenham na instituição de saúde:

Entrevista, avaliação das crianças, curativos $e$ palestras educativas [...]. Supervisiona a prática dos alunos e dá palestras para os pacientes, retirada de cateter, sistematização da assistência de enfermagem (enfermeira-2).

\section{[...] tanto atividades em grupo, como atendimento} individualizado (terapeuta ocupacional-1).

Tem atividades sociais, discussões de casos, atendimento aos pacientes [...]. Admissão, alta e encaminhamentos, anotações em prontuário, conferência de censo, etc. (enfermeira-5).

\section{[...] procedimentos de enfermagem de uma maneira geral e maior envolvimento nas atividades desenvolvidas (enfermeira-7).}

Diante dos depoimentos concordamos com Silva, Silva e Oliveira ${ }^{(8)}$ quando afirmam haver evidente desconsideração do caráter pedagógico do campo de estágio, no qual as atividades não são direcionadas no sentido de promover uma aprendizagem significativa, mas, antes, os estagiários devem realizar atividades que os supervisores diretos consideram importantes ou necessárias. Isto, quase sempre, se restringe à realização de procedimentos estritamente técnicos. Desse modo, o estagiário muitas vezes assume o papel 
de mão-de-obra disponível e exige-se dele pleno domínio do conhecimento teórico e técnico, a despeito de jamais, ter tido oportunidade de realizar alguns procedimentos.

Consoante às falas dos participantes, as práticas dos docentes refletem ainda uma prática tecnicista. No entanto, revelam também um desejo de transformação - embora silencioso, por meio de trabalhos de educação em saúde.

Exemplarmente, a Universidade de FortalezaUNIFOR vem incentivando mudanças, mediante implementação da metodologia da problematização nos cursos; estímulo à participação ativa do aluno na aprendizagem; emprego de tecnologias avançadas, como a confecção de CD e da educação a distânciaEAD; novos ambientes para o processo ensinoaprendizagem; integração da pesquisa como parte do processo de ensino-aprendizagem e capacitação dos docentes. Devemos entender que o aluno deve ser formado sob a ótica de integralidade. Ao unirmos a técnica à ciência, o saber fazer ao saber por quê, vamos encontrar na proposta de diretrizes curriculares para a área da saúde a clara expressão dessa visão.

Por isso, a formação do aluno requer habilidades cognitivas, técnicas e afetivas. Alcançar todos esses aspectos exige mais do que a transmissão de conteúdos das denominadas matérias de ensino. Requer todo um conjunto de ações e procedimentos dos agentes do processo educativo-docentes e profissionais de saúdearticulados entre si. Nesse sentido, podemos reafirmar a necessidade do envolvimento de todos - docentes e profissionais de saúde - na formulação da proposta educativa.

\section{Estratégias para fortalecer a parceria com o serviço}

Inúmeras estratégias passíveis de ser implementadas para fortalecer a parceria com o serviço evidenciam o interesse da universidade em articular a IDA - realizando cursos de qualificação docente com a participação dos profissionais de saúde, contribuindo com material hospitalar, promovendo eventos em parceria com as instituições de saúde e até mesmo disponibilizando material gráfico e compras de livros quando solicitado pela instituição de saúde.

A instituição preparou uma sala que será destinada ao nosso laboratório de informática, com o intuito de prepararmos as famílias para o mercado de trabalho. No entanto, necessitamos de computadores e acreditamos que a instituição poderá ajudar nos doando tais equipamentos, fortalecendo nossa parceria (enfermeira-1).

[...] cursos oferecidos na universidade poderiam ser oferecidos para os profissionais do hospital [...] realizar apresentação dos casos e expor as sugestões para melhoria do serviço [...]. Incentivo no aprendizado dos profissionais através de cursos [...]. Oferecer reuniões científicas com os profissionais da casa (fisioterapeuta-1).

Estimular estágios voluntários dos alunos, favorecer a monitoria, promover palestras de outros profissionais de saúde para os residentes e funcionários do local. [...] os estágios deveriam ser contínuos e não só uma vez na semana (terapia ocupacional-1).

Como mostra o relato da terapeuta ocupacional1, a descontinuidade dos estudantes obriga a interrupção das atividades e a repetição de mensagens e ações, o que desgasta a IDA e dificulta o trabalho da equipe.

Ter maior entrosamento entre a escola e o curso, para tomar mais conhecimento do trabalho feito $e$ das principais necessidades em relação a nossa clientela. Propor atividades de integração com a família das crianças (educador físico-1).

Na minha opinião, as estratégias já estão acontecendo. Os alunos estão vindo uma vez por semana e estão participando muito bem desta tarde, dentro do posto de saúde e na comunidade, dando palestras e conhecendo a rotina de trabalho dos profissionais (odontólogo-1).

Contratando os profissionais da instituição para preceptoria [...]. Manter sempre contato e estreitar cada vez mais a parceria [...] contribuição na aquisição de novos equipamentos (fonoaudiólogo1).

Oferecer vagas de especialização/mestrado, sem ônus para os enfermeiros da instituição; disponibilizar maior quantidade de material médico-hospitalar certificados pela ANVISA [...]; doação de material permanente de difícil aquisição para o hospital tipo: gelágua, água mineral, frigobar, geladeira [...] (enfermeira-7). 
Conhecimentos, habilidades ou atitudes são adquiridos pelo exercício das ações, pois aprender fazendo é mais eficiente que receber informações passivamente. Assim, a estratégia educacional deve ser o treinamento em serviço, o que possibilita a prática de ações de complexidade crescente, conforme as exigências do serviço e do programa de ensino. Urge as escolas/instituições se empenharem para assegurar oportunidades de aprendizagem ativa, que permitam experiências pessoais significativas e motivadoras.

\section{CONSIDERAÇÕES FINAIS}

Os participantes deste estudo apontaram que a relação dos profissionais da assistência com os docentes é bastante positiva e acreditam numa integração quando existe boa relação com o docente ou quando os discentes realizam as atividades da unidade independente de parceria com o docente.

Percebedos nas falas dos particípes deste estudo que suas contribuições estão relacionadas com sua disposição em ajudar quando solicitado ou em favorecer o campo de prática para professor/aluno mediante seleção de pacientes com casos clínicos importantes, não execução de procedimentos técnicos, cedendo lugar para o aluno e também para a troca de experiência.

As ações desenvolvidas pelos docentes resumem-se em prestar assistência, distribuir tarefas, supervisionar a prática e acompanhar os alunos. Mas o docente também é um facilitador e ele precisa compreender que sua função significa ir além da transmissão de conhecimentos. É fundamental incentivar e apoiar estudos que aprofundem tanto as ideias e percepções dos docentes e profissionais de saúde como suas representações e aspirações sobre IDA.

Estratégias vêm sendo implementadas pela universidade para fortalecer a parceria com o serviço. Certamente, a IDA envolve questões estruturais e conjunturais muito mais complexas. Diante disto, são necessários momentos de reflexão sobre como articular esses dois contextos aparentemente desconectados universidade e serviços, buscando ligar os espaços de formação aos diferentes cenários da vida real e de prestação de cuidados à saúde. Portanto, com vistas à integração docente-assistencial sob a ótica dos profissionais de saúde, mencionadas propostas devem ser implementadas. Desse modo, poderemos obter o êxito esperado com a devida aplicação da IDA.

\section{REFERÊNCIAS}

1. Shimizu HE. A percepção de docentes do curso de graduação em enfermagem e obstetrícia de uma universidade pública federal sobre a integração docente assistencial. Rev Latino-Am Enferm. 1999 Dez;7(5):51-7.

2. Miranda CML, Carvalho V, Souza EF. Integração docente assistencial: uma questão "não resolvida". Esc Anna Nery Rev Enferm. 1997 Dez; 1(2):73-82.

3. Duarte NMN. Integração docente assistencial entre uma instituição de ensino e um hospital de ensino de PortoAlegre: experiência de um grupo de trabalho. Rev Gauch Enferm. 1990 Dez;11:52-8.

4. Olschowsky A, Silva GB. Integração docenteassistencial: um estudo de caso. Rev Esc Enferm USP. 2000 Jun;34(2):128-37.

5. Padilha MICS. Análise crítica das causas da integração e/ou desintegração docente assistencial na enfermagem. Rev Gaúch Enferm. 1991 Jan;12(1):33-7.

6. Ministério da Saúde (BR). Resolução 196, de 1996. Pesquisa envolvendo seres humanos. Brasília: Ministério da Saúde; 1996.

7. Bardin L. Análise de conteúdo. Lisboa: Edições 70; 2004.

8. Silva CC, Silva ATMC, Oliveira AKS. Processo avaliativo em estágios supervisionados: uma contribuição para o estudo. Cogitare Enferm. 2007 Out/Dez;12(4):428-38.

9. Delors J. Educação: um tesouro a descobrir. $8^{a}$ ed. São Paulo: Cortez, UNESCO/MEC; 2003.

10. Shon DA. The reflective practitioner. New York: Basic Books Inc; 1983.

11. Sacristán FG. O currículo, uma reflexão sobre a prática. $3^{\mathrm{a}}$ ed. Porto Alegre: Artmed; 1998.

12. Fonsenca AD, Zappas S. O que é ser facilitadora no curso de especialização em projetos assistenciais de enfermagem. Texto Contexto Enferm. 1999;8(esp.):63-8.

13. Shimizu HE. A percepção de docentes do curso de graduação em enfermagem e obstetrícia de uma universidade pública federal sobre a integração docente-assistencial. Rev Latino-Am Enferm. 1999 Dez;7(5):51-7.

14. Almeida M., Feuerwerker L, Llanos M, organizadores. Educação dos profissionais de saúde na América Latina: teoria e prática de um movimento de mudança. São Paulo: Hucitec; Buenos Aires: Lugar Editorial; Londrina: UEL; 1999.

15. Zampieri MFM, Barbosa SFF. A experiência de ser facilitadora em um projeto assistencial: um desafio prazeroso. Texto Contexto Enferm. 1999;8(esp.):51-61. 